\title{
REGIONAL ANALGESIC EFFECT OF EPIDURAL MORPHINE IN VOLUNTEERS
}

\author{
W.R. Thompson, P.T. Smith, M. HiRst, G.P. Varkey and R.L. KNILL
}

\begin{abstract}
Limb ischaemia induced by a sub-maximum effort tourniquet technique was used to characterize the analgesic effects of lumbar epidural morphine in volunteers. As an index of pain threshold, we measured the time to perception of pain in an upper and a lower limb before and at intervals up to six hours following epidural injections of morphine $3.5 \mathrm{mg}$ and $7.0 \mathrm{mg}$, and before and after subcutaneous injections of the same doses. Subcutaneous morphine had no significant effect on the times to perception of pain in either limb. Lumbar epidural morphine did not alter upper limb times. but markedly delayed the onset of pain in the lower limbs. This lower limb analgesic effect was apparent thirty minutes after injection, peaked at about ninety minutes and was still present after six hours. Serum levels of morphine were nearly identical after subcutaneous and epidural injections of the same dose. We conclude that lumbar epidural morphine produces marked analgesia for this type of experimental pain primarily by a "regional" effect rather than as a result of systemic absorption. This regional effect develops slowly and is prolonged.
\end{abstract}

KEY WORDS: ANALGESIA, Epidural morphine, regional effect.

ALTHOUGH a SPINAL ACTION of narcotics had been suspected for many years,' it was only recently discovered that small doses of narcotic placed directly into the sub-arachnoid space of animals could produce behavioural analgesia, ${ }^{2}$ apparently by binding to specific receptors in the dorsal horn of the spinal cord, ${ }^{3,4}$ and so reducing central transmission of peripheral noxious stimuli s-8. $^{s-1}$.

Both intrathecal and epidural morphine have now been carefully tested for analgesic effectiveness in human patients with pathological pain. In double-blind cross-over studies employing placebo controls, lumbar intrathecal morphine 0.5 $1,0 \mathrm{mg}$ was observed to relieve severe "intractable" pain associated with cancer of the pelvis, and lumbar epidural morphine $2-6 \mathrm{mg}$ to reduce pain after upper abdominal surgery. ${ }^{10}$ In each case. the quality of analgesia was better than that associated with commonly used intramuscular

W.R. Thompson, M.B., B.S., F.F.A.R.A.C.S., Fellow, Department of Anaesthesia (Present Address: Sir Charles Gairdner Hospital, The Queen Elizabeth II Medical Centre, Nedlands, W. Australia); P.T. Smith, B.Sc.; M. Hirst, Ph.D., Professor, Department of Pharmacology; G.P. Varkey, M.B., B.S., F.R.C.P.(C), Associate Professor and R.L. Knill, M.D., F.R.C.P.(C), Associate Professor, Department of Anaesthesia, University of Western Ontario, London, Canada.

Reprint requests to: Dr. R.L. Knill, Department of Anaesthesia, University Hospital, P.O. Box 5339.

Postal Station A, London, Ontario. Canada N6A 5A5. doses of morphine. ${ }^{9,10}$ For extended analgesic therapy, the epidural route of administration would be preferred to the intrathecal, as it avoids the added risks associated with repeated subarachnoid punctures.

There is only limited information on the pharmacokinetics and pharmacodynamics of epidurally administered narcotic. Preliminary data suggest that after epidural injections of morphine and meperidine in man, narcotic appears in the lumbar cerebrospinal fluid (CSF) within minutes, with local CSF concentrations becoming maximal in about 30 minutes. ${ }^{11.12}$ The analgesia produced is reported to be "regional" or "segmental" in nature, ${ }^{13-15}$ but its onset, magnitude and duration are unclear, seeming to vary considerably between individual patients - perhaps partly dependent upon the origin and type of pain being treated and, in some instances, the clinical condition in which pain has occurred. ${ }^{12.16 .17}$

The purpose of this study was to examine in a sensitive way certain characteristics of epidural morphine analgesia in man - in particular the proposed "regional" analgesic effect versus a possible effect related to systemic absorption and its time course. As we wished to quantitate pain relief in controlled conditons over several hours, we studied responses to a standardized type of experimental pain in volunteers. This study was conducted in conjunction with measurement of ventilatory effects, which are described in an accompanying report. ${ }^{18}$

Can. Anaesth. Soc. J., vol. 28, no. 6, November 1981 


\section{Methods}

The study was approved by the University of Western Ontario Committee on Human Research.

The subjects were four healthy male volunteers who were right-handed, normotensive and free of pain. None had been exposed to narcotic recently; none had a history of drug allergy. Each was familiarized with the nature and purpose of the investigation and gave his informed consent.

The plan was to compare analgesic effects of morphine $3.5 \mathrm{mg}$ and $7.0 \mathrm{mg}$ given by the subcutaneous route and by epidural injection in the lumbar region. Each of the four possible doseroute combinations was to be studied in each subject, with the individual studies of each subject separated by at least a week. Analgesia would be assessed in two regions, an upper and a lower limb, over several hours following each type of injection.

Studies began with a control "tourniquet test" - a method of inducing and estimating pain threshold - in an upper and a lower limb. Next, morphine was administered, subcutaneously or epidurally, in a dose of 3.5 or $7.0 \mathrm{mg}$. Over the subsequent 4-6 hours, the "tourniquet tests" were repeated and in addition venous blood was sampled for determination of serum morphine levels, both according to the schedule in Table $\mathrm{I}$.

Subcutaneous injections were made into the right upper arm. For epidural administrations, subjects were positioned on the left side, and a Tuohy \# 18 epidural needle was inserted into the epidural space at the L3-L4 interspace. Morphine for epidural injection was a solution of preservative-free morphine $3.5 \mathrm{mg}$ or $7.0 \mathrm{mg}$, diluted to $10 \mathrm{ml}$ with sterile normal saline. Local anaesthetic was not injected into the epidural space. Except during epidural injections, subjects remained in the supine position throughout all phases of the study.
The "tourniquet test" was a modification of the sub-maximum effort tourniquet technique of Smith, et al. ${ }^{19}$ At each "tourniquet test" time (Table I), tests were done separately in the arm and the leg of the non-dominant side, with the arm-leg sequence randomized and three minutes rest allowed between individual limb tests. A twenty-four inch tourniquet cuff (Zimmer \#3120846) was applied to the proximal portion of a limb, and the limb was elevated to $90^{\circ}$ for sixty seconds to drain venous blood. We inflated the cuff to $35 \mathrm{kPa}$ with a calibrated inflator (Kidde), and the subject immediately lowered and began to exercise the limb, following a predetermined exercise routine. (The particular routines were set to produce similar times to perception of pain in upper and lower limbs.) For the arm, the exercise consisted of twenty squeezes of a hand dynamometer (Jamar) to a force of 14 newtons, in a cycle of a squeeze sustained for one second, followed by a one second period of rest. To exercise the leg, the foot was placed against a vertical spring-loaded hinged pedal and the subject performed sixty plantar flexons requiring a force of 7 newtons and an excursion of $10 \mathrm{~cm}$, at a rate of one flexion per second. The timing for both exercise routines was called out by an investigator with a stop watch. After completing the exercise and with the tourniquet still inflated, the subject rested his limb and awaited the onset of a definite deep ache in the forearm or calf. When the subject first perceived this pain clearly, the cuff was immediately released. The time to onset of pain was measured from the end of the period of exercise.

Samples of blood were immediately separated into two portions of at least $5 \mathrm{ml}$, for duplicate analysis of serum morphine levels. Total serum morphine was measured using high performance liquid chromatography with a reverse-phase column (Altex Ultrasil-Octyl $10 \mu \mathrm{m}$ ) and a glassy carbon electrode detector cell (Bioanalytical Sys-

TABLE I

TEST SCHEDULe

\begin{tabular}{|c|c|c|c|c|}
\hline \multirow[b]{2}{*}{ Time } & \multicolumn{2}{|c|}{$\begin{array}{l}\text { Subcutaneous Morphine } \\
3.5 \mathrm{mg} \text { and } 7.0 \mathrm{mg}\end{array}$} & \multicolumn{2}{|c|}{$\begin{array}{l}\text { Epidural Morphine } \\
3.5 \mathrm{mg} \text { and } 7.0 \mathrm{mg}\end{array}$} \\
\hline & $\begin{array}{l}\text { Tourniquet } \\
\text { Tests }\end{array}$ & $\begin{array}{l}\text { Blood Sample for } \\
\text { Serum Morphine }\end{array}$ & $\begin{array}{l}\text { Tourniquet } \\
\text { Tests }\end{array}$ & $\begin{array}{l}\text { Blood Sample for } \\
\text { Serum Morphine }\end{array}$ \\
\hline Control & $*$ & & $*$ & \\
\hline $30 \mathrm{~min}$. & & * & $*$ & * \\
\hline 90 min. & * & * & * & * \\
\hline $150 \mathrm{~min}$. & & * & * & * \\
\hline $240 \mathrm{~min}$. & * & * & * & * \\
\hline $360 \mathrm{~min}$. & & & $*$ & \\
\hline
\end{tabular}




\begin{tabular}{|c|c|c|c|c|}
\hline & \multicolumn{3}{|c|}{$\begin{array}{c}\text { TABLE II } \\
\text { TIMES TO ONSET OF PAIN (SECONDS) } \\
\text { MORPHINE } 3.5 \mathrm{mg} \\
\mathrm{n}=4\end{array}$} & \\
\hline & \multicolumn{2}{|c|}{ Subcutaneous } & \multicolumn{2}{|c|}{ Epidural } \\
\hline & Arm & Leg & Arm & Leg \\
\hline $\begin{array}{l}\text { Control } \\
30 \mathrm{~min} . \\
90 \mathrm{~min} . \\
150 \mathrm{~min} . \\
240 \mathrm{~min} . \\
360 \mathrm{~min} .\end{array}$ & $\begin{array}{l}126 \pm 29 \\
167 \pm 84 \\
139 \pm 41\end{array}$ & $\begin{array}{l}131 \pm 29 \\
170 \pm 79 \\
120 \pm 37\end{array}$ & $\begin{array}{l}126 \pm 29 \\
114 \pm 21 \\
130 \pm 30 \\
123 \pm 34 \\
127 \pm 30 \\
115 \pm 30\end{array}$ & $\begin{array}{l}126 \pm 30 \\
234 \pm 20 \\
385 \pm 60^{*} \dagger \\
462 \pm 135^{*} \dagger \\
375 \pm 153^{*} \dagger \\
311 \pm 138\end{array}$ \\
\hline
\end{tabular}

All values are means \pm S.E.M.

Within the analysis of variance:

* Significantly different from control values, $p<0,05$.

†Significantly different from concurrent arm values, $p<0.05$.

Overall significant difference between leg and arm values after epidural, $p<0.05$.

tems LC2A). For sample preparation, the internal standard dihydromorphone ( $40 \mathrm{ng}$ ) was added to serum $(500 \mu \mathrm{l})$ along with bicarbonate buffer (pH 8.9, $100 \mu \mathrm{l}$ ) and isopropyl alcohol in ethyl acetate $(2: 98,750 \mu 1)$. This mixture was vortexed ( 10 seconds) and centrifuged. The organic layer was then transferred to a tube containing $0.01 \mathrm{M}$ hydrochloric acid $(100 \mu \mathrm{l})$ and vortexed again. After centrifugation, the organic layer was aspirated off and the remaining aqueous layer injected into the chromatograph. Serum concentrations were determined by integrating peak areas and comparing observed values to a standard prepared from extracted samples containing known amounts of morphine and internal standard.

Data on times to onset of pain were assessed with a computerized analysis of variance, employing a "BMDP" software package. ${ }^{20}$ Data on serum morphine levels were assessed with a paired t-test. In all analyses, $p$ values of 0.05 or less were accepted as indicative of a significant difference.

\section{RESULTS}

No side effects were observed after subcutaneous morphine, but they were frequent after epidural morphine. After $3.5 \mathrm{mg}$ by the epidural route they were relatively mild and included slight itching during the study ( 3 subjects), nausea in the first hours following the study ( 2 subjects) and urinary hesitancy or a slow stream for the subsequent twelve hours or so (3 subjects). After $7.0 \mathrm{mg}$ epidurally however, the first two subjects experienced marked dysphoria and nausea, and one vomited repeatedly, beginning about the time they were beginning to mobilize at the end of the study period. In addition, both were unable to void for the first eight hours following the $7.0 \mathrm{mg}$ study, and for an additional twelve hours noted hesitancy and a slow stream. * These unpleasant side effects deterred us from further studies at the $7.0 \mathrm{mg}$ dose. Results of the completed $7.0 \mathrm{mg}$ studies are reported. even though with only two subjects they could not be analyzed statistically.

Times to onset of pain with the "tourniquet test" are summarized for morphine $3.5 \mathrm{mg}$ in Table II, and for morphine $7.0 \mathrm{mg}$ in Table III. Subcutaneous morphine did not significantly alter times in either the arm or the leg and epidural morphine did not alter arm times. Lumbar epidural morphine $3.5 \mathrm{mg}$, however, significantly delayed the onset of pain in the leg at 90 , 150 and 240 minutes after injection and, overall, delayed pain in the leg compared to the arm ( $p<$ 0.05 ). Epidural morphine $7.0 \mathrm{mg}$ appeared to have similar effects. Subjects reported that, with epidural morphine, the discomfort in the calf was not only slower in onset, but tended to be more vague; however, they were unaware of any altered "reaction" to pain.

Serum levels of total morphine are summarized in Figure 1. Differences between levels after subcutaneous and epidural administrations of $3.5 \mathrm{mg}$ were not statistically significant. The half-times of levels between 30 and 240 minutes after injections ranged from 73 to 105 minutes.

Statistical analyses suggested that the effect of epidural morpine on onset of pain in the leg was a quadratic function of time $(p<0.06)$. To further

* There was also delayed ventilatory depression which is described in an accompanying report. ${ }^{18}$ 
TABLE III

Times to ONSET of Pain (SEConds)

MORPHINE $7.0 \mathrm{mg}$

$$
\mathrm{n}=2
$$

\begin{tabular}{lccccr}
\hline \hline & \multicolumn{2}{c}{ Subcutaneous } & & \multicolumn{2}{c}{ Epidural } \\
\cline { 2 - 3 } \cline { 5 - 6 } & Arm & Leg & & Arm & Leg \\
\hline Control & 80 & 66 & & 122 & 65 \\
$30 \mathrm{~min}$. & & & & 125 & 292 \\
$90 \mathrm{~min}$. & 100 & 85 & & 103 & 357 \\
$150 \mathrm{~min}$. & & & & 104 & 280 \\
$240 \mathrm{~min}$. & 80 & 75 & & 110 & 265 \\
$360 \mathrm{~min}$. & & & & 107 & 222 \\
\hline
\end{tabular}

All values are means.

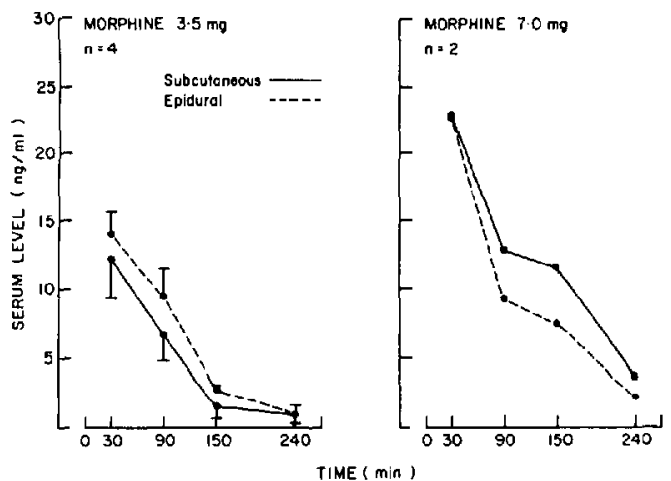

Figure I Serum concentrations of total morphine after subcutaneous and epidural injections of $3.5 \mathrm{mg}$ (left, means \pm S.E.M.) and $7.0 \mathrm{mg}$ (right. means only). There was no statistically significant difference between scrum concentrations after subcutaneous and epidural injections of morphine $3.5 \mathrm{mg}$.

analyze this time course of effect, we converted individual delays in onset of pain to per cent of maximum effect where

Per cent of Maximum Effect $=$

$$
\frac{\text { observed time - control time }}{\text { maximum time - control time }}
$$

Group values based on data from all six epidural morphine studies, considering $3.5 \mathrm{mg}$ and $7.0 \mathrm{mg}$ data together, are shown in Figure 2. Delays of pain in the leg, expressed as per cent of maximum effect, were greater than control at all intervals following epidural injections, that is at 30,90, 150,240 and 360 minutes (within analysis of variance, $p$ values $<0.02$ ). In addition, 90 minute values appeared greater than those at 30 minutes $(p<0.08)$ and at 360 minutes $(p<0.05)$.

\section{Discussion}

The results indicate that epidural morphine produces marked regional analgesia which develops slowly and is prolonged.

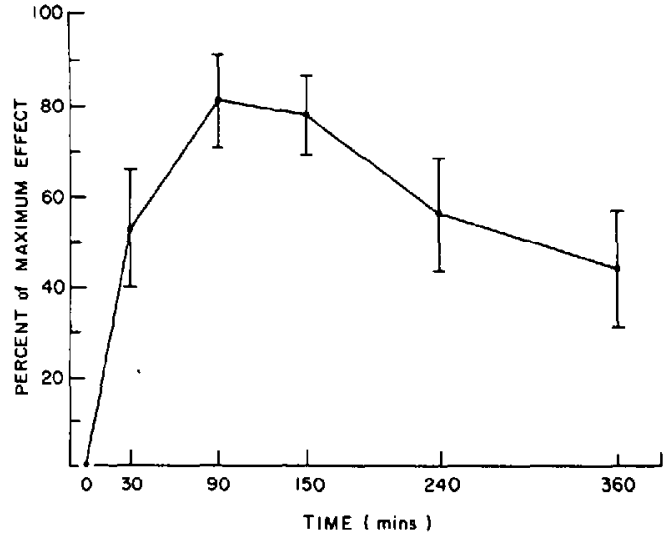

Figure 2 Time course of regional analgesic effect of lumbar epidural morphine. Points represent delays of onset of pain in the leg, expressed as per cent of maximum effect (see text), after both doses of epidural morphine (all data grouped, means \pm S.E.M.). Values were grcater than control at all times following epidural injection; in addition, values at 90 minutes were greater than those observed at 30 and 60 minutes.

The particular questions posed by this study necessitated use of an experimental pain model which, although artificial in nature (i.e. without the stress engendered by pathological pain) does permit measurement of pain perception in an environment relatively free of variable "noise" .21,22 The experimental pain was ischaemic in origin, produced by a limb tourniquet inflated to above arterial systolic blood pressure, together with a short period of sub-maximum exercise. ${ }^{19}$ Pain induced in this manner evolves slowly over several minutes and is reasonably reproducible in both time of onset and rate of progression, provided that the exercise routine is carefully standardized. ${ }^{19,23}$ Delay in the first perception of pain indicates elevation of the pain threshold or analgesic effect and the magnitude of delay relates in an approximate way to intensity of analgesia. ${ }^{19}$ For studying analgesics, this model is considered superior to other types of experimental pain. ${ }^{19,22,24}$

We had originally planned to determine the effects of two doses of morphine, $3.5 \mathrm{mg}$ and $7.0 \mathrm{mg}$, administered by both the subcutaneous and epidural routes in all four subjects, but had to terminate the $7.0 \mathrm{mg}$ studies after two subjects experienced unpleasant side effects. The results of the two studies at $7.0 \mathrm{mg}$ are being reported, even though they could not be analyzed statistically.

Not surprisingly, subcutaneous morphine $3.5 \mathrm{mg}$ in these healthy volunteers appeared to have no more than a slight analgesic effect. There 
were no significant delays in onset of pain with the "tourniquet tests" (Table II) and serum levels of morphine were all less than $25 \mathrm{ng} / \mathrm{ml}$ (Figure 1) which is the serum concentration of morphine suggested by the analysis of Berkowitz, et al to be necessary for minimal analge sia. ${ }^{25}$

Lumbar epidural morphine $3.5 \mathrm{mg}$, which resulted in serum levels similar to subcutaneous administration of $3.5 \mathrm{mg}$ (Figure 1), did not alter perception of pain in the arm, but delayed the onset of pain in the leg considerably (Table II) indeed much more than intravenous morphine $15 \mathrm{mg}$ evaluated with the same tourniquet test ${ }^{14}-$ suggesting a relatively intense analgesic effect. The $7.0 \mathrm{mg}$ dose produced qualitatively similar changes; unfortunately the incomplete data do not permit an assessment of dose relationships (Table III).

That analgesia after epidural morphine was due primarily to a regional action rather than to vascular absorption and consequent systemic effect, is suggested by the following observations: (1) a significant delay in perception of pain in the leg after epidural morphine together with an absence of effect in the arm and a significant difference between the two (Table II), (2) an absence of detectible effect in the lower limb after subcutaneous injections which produced similar serum levels of morphine (Table II, Figure 1) and (3) an increasing analgesic effect in the lower limb between 30 and 90 minutes after epidural injections when serum morphine levels were decreasing rapidly (Figures 1 and 2 ). The extent of the regional effect could not be ascertained by these experiments.

Our observations therefore indicate that the analgesic effect of lumbar epidural morphine was potent and mainly "regional". Both characteristics are in keeping with numerous clinical reports suggesting that small doses of epidural narcotic produce better analgesia than would be expected of the same doses administered by systemic routes. ${ }^{12,17,26}$ The indication of a "regional" or "segmental" effect corroborates the conclusions of two previous studies of volunteers who were subjected to other types of experimental pain. ${ }^{13.14}$ This profound and regional analgesia is presumably due to anatomical localization of relatively high concentrations of the drug within segments of the spinal cord which subserve the region of noxious stimulation. ${ }^{8}$

Our experimental model of pain was sensitive enough to permit an assessment of the time course of regional analgesic effect if delays in pain perception were expressed as per cent of maximum effect. On the basis of these data, analgesia was estimated to onset within $30 \mathrm{~min}$ utes, to peak about 90 minutes and to persist for at least six hours (Figure 2).

The indication of a slow rate of progression to peak analgesic effect is in keeping with the observations of Torda, et al. who, studying volunteers with a less sensitive assessment of pain threshold, failed to detect analgesia 75 minutes after lumbar epidural morphine, but found it to be present at three hours. ${ }^{13} \mathrm{~A}$ slow development of maximum analgesia can be explained by a slow migration of narcotic from the epidural space through to the CSF and thence to the cord and the dorsal horns, which would not be too surprising in view of the facts that morphine diffuses poorly through tissues ${ }^{8,27}$ and that affected spinal cord segments were at a distance (cephalad) from the site of injection. Our observation of a prolonged duration of analgesia is in agreement with the clinical impressions of several groups. ${ }^{12,16,17,26}$ This was no doubt due to a slow rate of clearance of morphine from the cord as a result of relatively high local concentrations of narcotic ${ }^{8,28}$ behaving as if tightly bound to central nervous system sites. ${ }^{27}$

A legitimate criticism of our study is that we did not "blind" subjects and observers to the nature of injections, i.e. epidural or subcutaneous. A wareness of pain is obviously a subjective phenomenon, open to conscious or subconscious bias, which may influence both subject reaction and subject-observer interaction. Two lines of evidence argue against this being important in this study. First, the times to onset of pain with the "tourniquet test" during peak analgesic periods ranged from 5 to 10 minutes - tourniquet times which in the absence of analgesia produce moderate to very distressing pain. ${ }^{19.23} \mathrm{We}$ doubt that bias would have consistently introduced this magnitude of analgesic effect. Second, there was a consistent increase in times to pain perception between 30 and 90 minutes after epidural injection and, as this finding was totally unexpected, it cannot be attributed to bias. In any case we would not have been able to blind three of our subjects as to the nature of epidural injections because they developed itching after epidural morphine and would have recognized this as one of its side effects.

Although it has been generally considered that the effects of intrathecal and epidural narcotics are purely "analgesic", our study suggests the probability of several additional neural effects. 
Like others, ${ }^{13}$ we have noted a high incidence of urinary hesitancy and a slow stream in volunteers after epidural morphine, effects which are presumably due to an action on the autonomic innervation of the urinary bladder at the level of the spinal cord. We also observed delayed dysphoria, nausea and vomiting, which we believe are the results of slow migration of morphine to rostral neural structures in the circulating CSF. ${ }^{18}$ The incidence of these additional effects seems higher in volunteers than in patients with clinical pain; ${ }^{29}$ whether this is a true difference in incidence or simply a difference in recognition on the part of the subject and/or observer is unclear.

In summary, this study shows that in healthy volunteers subjected to experimental ischaemic pain, the analgesia produced by small doses of morphine injected into the epidural space has four characteristics - it is intense, regional, slowly-developing and prolonged.

\section{ACKNOWLEDGEMENTS}

The authors wish to thank the volunteers who participated in our study, Miss J. Clement who provided expert technical assistance, Mrs. Karen Campbell for assistance in statistical analysis and Mrs. L. Nolan who helped prepare the manuscript.

\section{REFERENCES}

1. WIKLER, A. Sites and mechanisms of action of morphine and related drugs in the central nervous system. Pharmacol. Rev. 2: 435-506 (1950).

2. YAKSH, T.L. \& RUDY, T.A. Analgesia mediated by a direct spinal action of narcotics. Science 192: 1357-1358 (1976).

3. Lamotte, C., Pert, C.B. \& Snyder, S.H. Opiate receptor binding in primate spinal cord: distribution and changes after dorsal root section. Brain Research 1/2: 407-412 (1976).

4. Atweh, S.F. \& Kuhar, M.J. Autoradiographic localization of opiate receptors in rat brain. I. Spinal cord and lower medulla. Brain Research I24: 53-67 (1977).

5. Besson, J.M., Wyon-Maillard, M.C., Benoist, J. M., Conseiller, C. \& Hamann, K.F. Effects of phenoperidine on lamina $\mathrm{V}$ cells in the cat dorsal horn. J. Pharmacol. Exp. Ther. 187: 2, 239-245 (1973).

6. Kitahata, L.M., Kosaka, Y., Taub, A., Bonikos, K. \& Hoffert, M. Lamina - specific suppression of dorsal-horn unit activity by morphine sulfate. Anesthesiology 41: 1, 39-48 (1974).

7. Duggan, A.W., Hall, J.G. \& Headley, P.M. Suppression of transmission of nociceptive impulses by morphine: Selective effects of morphine administered in the region of the substantia gelatinosa. Br. J. Pharmacol. 61: 65-76 (1977).

8. YAKSH, T.L. \& RUDY, T.A. Narcotic Analgetics:
CNS sites and mechanisms of action as revealed by intracerebral injection techniques. Pain 4: 299-359 (1978).

9. Wang, J.K., Nauss, L.A. \& Thomas, J.E. Pain relief by intrathecally applied morphine in man. Anesthesiology 50: 149-151 (1979).

10. Anderson, I., Thompson, W.R., Varkey, G.P. \& KNILL, R.L. Lumbar epidural morphine is an effective analgesic following cholecystectomy. Can. Anaesth. Soc. J. 28: (1981).

11. Cousins, M.J., Mather, L.E.. Glynn, C.J, Wilson, P.R. \& Graham, J.R. Selective spinal analgesia. Lancet I: 1141-1142 (1979).

12. Magora, F.. Olshwang, D., Eimerl. D. Shorr, J., Katzenelson, R., Cotev, S. \& DAVIDSon, J.T. Observations on extradural morphine analgesia in various pain conditions. $\mathrm{Br} . \mathrm{J}$. Anaesth. 52: 247-252 (1980).

13. Torda, T.A., Pybus, D.A., Liberman, H. Clark, M. \& Crawford, M. Experimental comparison of extradural and I.M. morphine. Br. J. Anaesth. 52: 939-942 (1980).

14. Bromage, P.R., Camporesi, E. \& Leslie, J Epidural narcotics in volunteers: Sensitivity to pain and to carbon dioxide. Pain 9: 145-160(1980).

15. Asari, H., Inoue, K., Shibata, T. \& Soga, T. Segmental effect of morphine injected into the epidural space in man. Anesthesiology $54: 1.75-77$ (1981).

16. TORDA, T.A. Epidural analgesia with morphine. A preliminary communication. Anaesth. Intens. Care 7: 367-370 (1979).

17. Bromage, P.R.. Camporesi, E. \& Chestnut, D Epidural narcotics for postoperative analgesia. Anesth. Analg. 59: 473-480 (1980).

18. KNill, R.L., Clement, J.L. \& Thompson, W.R Epidural morphine causes delayed and prolonged ventilatory depression. Can. Anaesth. Soc. J. 28: 537-543 (1981).

19. Smith, G.M., Lowenstein, E., Hubbard, J.H. \& BEECHER, H.K. Experimental pain produced by the submaximum effort tourniquet technique: further evidence of validity. J. Pharmacol Exp. Ther. 163: 468-474 (1968).

20. Dixon, W.J. \& Brown, M.B. Biomedical computer program - P-series, Berkeley: University of California Press (1979).

21. BEECHER, H.K. Measurement of subjective responses, Chapter 2, New York: Oxford University Press (1959).

22. Parry, J.W.L. The evaluation of analgesic drugs. Anaesthesia 34: 468-475 (1979).

23. Moore, P.A., Duncan, G.H., ScotT, D.S. GreGG, J.M. \& GHIA, J.N. The submaximal effort tourniquet test: Its use in evaluating experimental and chronic pain. Pain 6: 375-382 (1979).

24. BeEcher, H.K. Measurement of subjective responses, Chapter 6, New York: Oxford University Press (1959).

25. Berkowitz, B.A., NGal, S.H., Yang, J.C. Hempstead, J. \& Spector, S. The disposition of morphine in surgical patients. Clin. Pharmacol. Ther. 17: 629-635 (1975).

26. Chayen, M.S., Rudick, V. \& Borvine, A. Pain control with epidural injection of morphine. Anesthesiology 53: 338-339 (1980).

27. Herz, A. \& Teschemacher, H.J. Activities and 
antinociceptive action of morphine-like analgesics. Advances in Drug Research 6: 79-119 (1971).

28. YaKSH, T.L. \& RUDY, T.A. Studies on the direct spinal action of narcotics in the production of analgesia in the rat. J. Pharmacol. Exp. Ther. 202: $41]-428$ (1977).

29. Reiz, S. \& Westrerg, M. Side-effects of epidural morphine. Lancet 2: 203-204 (1980).

\section{RÉSUMÉ}

L'ischémie expérimentale d'une extrémité produite par le reserrement du garrot a été utilisée pour l'étude des effets analgésiques de la morphine épidurale lombaire sur des volontaires. Nous avons mesuré le temps de perception de la douleur ischémique aux membres supérieur et inférieur avant et à intervalles variés allant jusqu'à six heures après injection épidurale de morphine $3.5 \mathrm{mg}$ et $7.0 \mathrm{mg}$, et avant et après des injections sous-cutanées des mêmes doses de morphine. La morphine sous-cutanée n'a modifié en rien le temps requis pour percevoir la douleur dans les deux membres. La morphine épidurale n'a pas modifié l'intervalle aux membres supérieurs mais a retardé de façon marquée le début de la douleur aux membres inférieurs. Cet effet analgésique aux membres inférieurs devient apparent 30 minutes après l'injection, atteint un maximum à environ 90 minutes et était encore manifeste après 6 heures. Les niveaux sériques de morphine était pratiquement les mèmes après injections épidurale et sous-cutanée d'une même dose. Les auteurs concluent que l'anesthésie lombaire épidurale à la morphine produit une analgésie importante sur ce type de douleur expérimentale et que cet effet est régional plutôt que systémique et qu'il se développe lentement et dure de façon prolongée. 